Check for updates

Cite this: RSC Adv., 2022, 12, 3569

Received 2nd January 2022

Accepted 11th January 2022

DOI: $10.1039 / \mathrm{d} 2 \mathrm{ra} 00010 \mathrm{e}$

rsc.li/rsc-advances

\section{Nickel-catalysed cross-electrophile coupling of aryl bromides and primary alkyl bromides $\uparrow$}

\author{
Nanxing Gao, (D) Yanshun Li (D) and Dawei Teng (D)* \\ The structure of primary alkylated arenes plays an important role in the molecular action of drugs and \\ natural products. The nickel/spiro-bidentate-pyox catalysed cross-electrophile coupling of aryl bromides \\ and primary alkyl bromides was developed for the formation of the $\mathrm{Csp}^{2}-\mathrm{Csp}^{3}$ bond, which provided an \\ efficient method for the synthesis of primary alkylated arenes. The reactions could tolerate functional \\ groups such as ester, aldehyde, ketone, ether, benzyl, and imide.
}

\section{Introduction}

Numerous attractive synthesis approaches to primary alkylated arenes have been developed, primarily based on the transition metal-catalysed addition of nucleophiles to electrophiles. ${ }^{1}$ Cross-electrophile coupling represents an important field in these modern organic synthesis reactions. ${ }^{2}$ In general, the direct use of electrophiles is convenient because electrophiles are more accessible and easier to use than nucleophiles in the coupling reactions. The cross electrophile coupling reactions catalysed by nickel metal catalysts can provide effective methods for the construction of new $\mathrm{C}-\mathrm{C}$ bonds in drugs and natural products. ${ }^{2 b, 3}$ Previous studies have established that 5$\mathrm{HT}_{2} \mathrm{~A}$ agonists have been implicated in cardiovascular function ${ }^{4}$ (Scheme 1). A class of histone deacetylase inhibitors has been generated from $N$-(2-amino-4-pyridyl)benzamide derivatives, which could be applied in the treatment of cancer, leukemia, and diseases related to differentiation and proliferation. ${ }^{5}$ Clobenpropit, a histamine $\mathrm{H}_{3}$-receptor antagonist, shows good activity in vitro at subnanomolar concentrations. ${ }^{6}$ Additionally, there are other alkylated alkanes derived from biologically important molecules such as estrones. ${ }^{7}$ Therefore, the development of a tremendous cross-electrophile coupling reaction between alkyl bromides and aryl bromides is still widely sought.

Recently, Charboneau et $a .^{8}$ used a dual metal catalytic system for cross-electrophile coupling reactions between aryl halides and alkyl halides (Scheme 2a). Perkins et al. ${ }^{9}$ demonstrated that the cross-electrophile coupling reaction catalysed by nickel catalyst could be achieved under metal-reductant-free electrochemical conditions (Scheme 2b). As part of an effort to develop nickel-catalysed cross-electrophile coupling reactions, we previously achieved a direct cross-electrophile coupling of

State Key Laboratory Base of Eco-Chemical Engineering, College of Chemical Engineering, Qingdao University of Science and Technology, Qingdao 266042, China.E-mail:dteng@qust.edu.cn

$\dagger$ Electronic supplementary information (ESI) available. See DOI: $10.1039 / \mathrm{d} 2 \mathrm{ra00010e}$ cyclic secondary alkyl bromides with aryl bromides. ${ }^{10}$ Owing to the good catalytic effect of spiro-bidentate-pyox ligands, we reasoned that they may also have a good catalytic effect in other types of cross-electrophile coupling reactions, which could lead to alkylated arenes (Scheme 2c).

\section{Results and discussion}

To identify whether the primary alkyl bromides and aryl bromides were competent, the coupling reaction of 4-bromobenzoate 1a with 1-bromo-3-phenylpropane 2a was surveyed (Table 1). Initial tests of nickel salts as metal catalysts for the cross-electrophile couplings were carried out using manganese as the reductant and $N$-methylpyrrolidone (NMP) as the solvent. Good catalytic performance was achieved using $\mathrm{NiBr}_{2}$ as the metal catalyst (entry 1). When $\mathrm{NiBr}_{2}$ was replaced by $\mathrm{NiI}_{2}$, $\mathrm{NiBr}_{2} \cdot$ glyme, or $\mathrm{NiCl}_{2}$, the yield of the desired cross-coupling product 3a decreased (entries 2-4). The desired product was not detected when the organic nickel catalyst $\mathrm{Ni}(\mathrm{acac})_{2}$ was used (entry 5). In order to optimize the reaction with different structures of the catalysts, we synthesized ligands with a substituted group on the pyridyl and phenyl ring L1b-L1d.

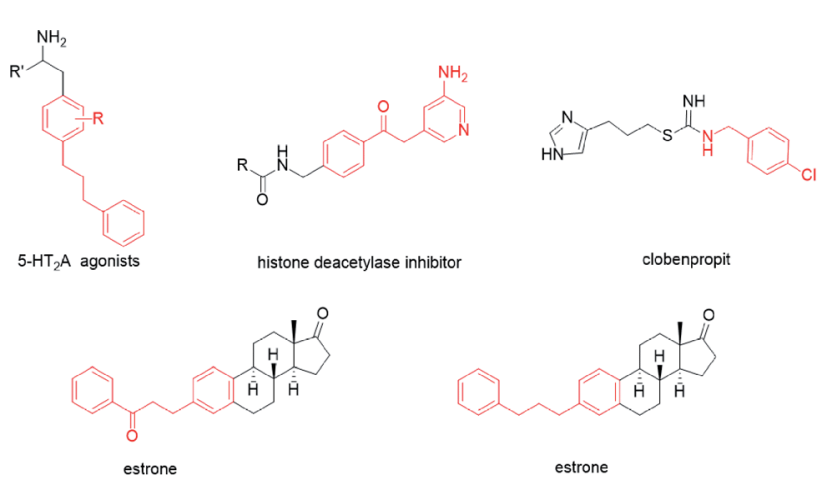

Scheme 1 Drugs with the structure of alkylated arenes. 


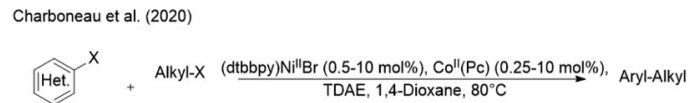

Perkins et al. (2019)
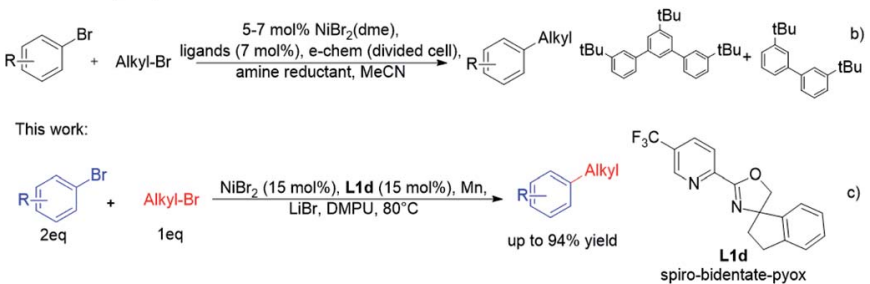

Scheme $2 \mathrm{Ni}$-catalysed cross-electrophile coupling between aryl bromides and primary alkyl bromides.

Using $\mathrm{NiBr}_{2}$ as the metal catalyst, ligand L1d with an electronwithdrawing group at the C5-position on the pyridine ring gave the cross-coupling product $3 \mathrm{a}$ in $72 \%$ yield, which is superior to the ligands L1a and L1c with electron-neutral or electron-donating groups as well as ligand L1b with a substituent group on the phenyl ring (entries 6-8). Other bidentate ligands, like L2-L5, did not yield better results (entries 9-12). Decreasing the temperature from $80{ }^{\circ} \mathrm{C}$ to $60{ }^{\circ} \mathrm{C}$ produced 3a only in $39 \%$ yield (entry 13). Raising the temperature to $100{ }^{\circ} \mathrm{C}$

Table 1 Scope of metal catalysts, ligands, and temperature ${ }^{a, b}$

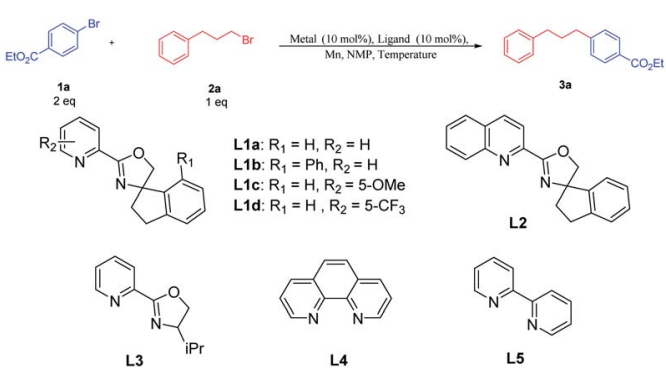

\begin{tabular}{lllll}
\hline Entry & Metal & Ligand & Temperature & Yield (\%) \\
\hline 1 & $\mathrm{NiBr}_{2}$ & L1a & $80{ }^{\circ} \mathrm{C}$ & 67 \\
2 & $\mathrm{NiI}_{2}$ & L1a & $80{ }^{\circ} \mathrm{C}$ & 62 \\
3 & $\mathrm{NiBr}_{2} \cdot$ glyme & L1a & $80{ }^{\circ} \mathrm{C}$ & 56 \\
4 & $\mathrm{NiCl}_{2}$ & L1a & $80{ }^{\circ} \mathrm{C}$ & Trace \\
5 & $\mathrm{Ni}_{2}(\mathrm{acac})_{2}$ & L1a & $80{ }^{\circ} \mathrm{C}$ & $\mathrm{NR}^{c}$ \\
6 & $\mathrm{NiBr}_{2}$ & L1b & $80{ }^{\circ} \mathrm{C}$ & 35 \\
7 & $\mathrm{NiBr}_{2}$ & L1c & $80{ }^{\circ} \mathrm{C}$ & 25 \\
8 & $\mathrm{NiBr}_{2}$ & L1d & $80{ }^{\circ} \mathrm{C}$ & 72 \\
9 & $\mathrm{NiBr}_{2}$ & L2 & $80{ }^{\circ} \mathrm{C}$ & Trace \\
10 & $\mathrm{NiBr}_{2}$ & L3 & $80{ }^{\circ} \mathrm{C}$ & 10 \\
11 & $\mathrm{NiBr}_{2}$ & L4 & $80{ }^{\circ} \mathrm{C}$ & 55 \\
12 & $\mathrm{NiBr}_{2}$ & L5 & $80{ }^{\circ} \mathrm{C}$ & 35 \\
13 & $\mathrm{NiBr}_{2}$ & L1d & $60{ }^{\circ} \mathrm{C}$ & 49 \\
14 & $\mathrm{NiBr}_{2}$ & L1d & $100{ }^{\circ} \mathrm{C}$ & 39 \\
15 & - & L1d & $80{ }^{\circ} \mathrm{C}$ & 0 \\
16 & $\mathrm{NiBr}_{2}$ & - & $80{ }^{\circ} \mathrm{C}$ & 0
\end{tabular}

${ }^{a}$ Reaction conditions: $1 \mathrm{a}(0.40 \mathrm{mmol}), 2 \mathrm{a}(0.20 \mathrm{mmol}), \mathrm{Mn}(0.60 \mathrm{mmol})$, ligand $(0.02 \mathrm{mmol})$, metal $(0.02 \mathrm{mmol})$, NMP $(1 \mathrm{~mL}) .{ }^{b}$ Isolated yield.

${ }^{c}$ No reaction. also resulted in a dramatic decrease in the yield (entry 14). In addition, no desired product was detected without $\mathrm{NiBr}_{2}$ or $\mathbf{L 1 d}$, which implied that the metal and ligand were indispensable for the coupling reactions (entries 15-16).

Following the evaluation of the metal catalysts, ligands, and temperatures, other reaction conditions were screened. Among the amide solvents, ${ }^{11}$ NMP can reach $72 \%$ yield under the reaction conditions (Table 2, entry 1). When N,N-dimethylformamide (DMF) and $N, N$-dimethylacetamide (DMA) were used as solvents, the yields were both decreased (entries 2 and 3). 1,3-Dimethyltetrahydropyrimidin-2(1H)-one (DMPU) proved to be the best solvent; the yield could reach $76 \%$ (entry 4 ). Catalyst loading screening found that the yield of $3 \mathbf{a}$ was promoted to $84 \%$ when the amounts of $\mathrm{NiBr}_{2}$ and $\mathbf{L 1 d}$ were both increased to $15 \mathrm{~mol} \%$ (entry 6), but the yield of 3a decreased when the loading of the metal and ligand were increased to $20 \mathrm{~mol} \%$ or decreased to $7.5 \mathrm{~mol} \%$ (entries 5 and 7). Further optimization found that the use of zinc instead of manganese as a reductant led to low yield (entry 8 ). The addition of one equivalent of lithium bromide boosted the yield to $91 \% ;^{12}$ however, lithium chloride was not as beneficial as we previously observed, ${ }^{10}$ and other additives did not generate better yields (entries 9-12). The screening of different loading of lithium bromide did not furnish a better result (entries 13-14).

Using the optimal reaction conditions, a range of substituted aryl bromides 1 were examined for the coupling reaction with 2a, furnishing a series of alkylated arenes 3 (Table 3). The challenging steric-hindered aryl bromide substrates $\mathbf{1 b}$ are reasonably tolerated, and the coupling product $\mathbf{3 b}$ was obtained in a slightly low yield. Additionally, aryl bromide with ester substituent at the meta-position of the benzene ring was

Table 2 Optimization of reaction conditions ${ }^{a, b}$

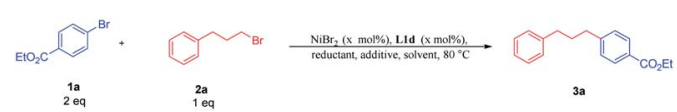

\begin{tabular}{llllll} 
Entry & Solvent & Additive & Temperature & Reductant & Yield (\%) \\
\hline 1 & NMP & - & $80{ }^{\circ} \mathrm{C}$ & $\mathrm{Mn}$ & 72 \\
2 & DMF & - & $80{ }^{\circ} \mathrm{C}$ & $\mathrm{Mn}$ & 40 \\
3 & DMA & - & $80{ }^{\circ} \mathrm{C}$ & $\mathrm{Mn}$ & 66 \\
4 & DMPU & - & $80{ }^{\circ} \mathrm{C}$ & $\mathrm{Mn}$ & 76 \\
$5^{c}$ & DMPU & - & $80{ }^{\circ} \mathrm{C}$ & $\mathrm{Mn}$ & 78 \\
$6^{d}$ & DMPU & - & $80{ }^{\circ} \mathrm{C}$ & $\mathrm{Mn}$ & 84 \\
$7^{e}$ & DMPU & - & $80{ }^{\circ} \mathrm{C}$ & $\mathrm{Mn}$ & 80 \\
8 & DMPU & - & $80{ }^{\circ} \mathrm{C}$ & $\mathrm{Zn}$ & 54 \\
9 & DMPU & $\mathrm{LiCl}$ & $80{ }^{\circ} \mathrm{C}$ & $\mathrm{Mn}$ & 61 \\
10 & DMPU & $\mathrm{LiBr}$ & $80{ }^{\circ} \mathrm{C}$ & $\mathrm{Mn}$ & 91 \\
11 & DMPU & $\mathrm{NaI}$ & $80{ }^{\circ} \mathrm{C}$ & $\mathrm{Mn}$ & 77 \\
12 & DMPU & $\mathrm{MgCl} 2$ & $80{ }^{\circ} \mathrm{C}$ & $\mathrm{Mn}$ & 26 \\
$13^{f}$ & DMPU & $\mathrm{LiBr}$ & $80{ }^{\circ} \mathrm{C}$ & $\mathrm{Mn}$ & 80 \\
$14^{g}$ & DMPU & $\mathrm{LiBr}$ & $80{ }^{\circ} \mathrm{C}$ & $\mathrm{Mn}$ & 90
\end{tabular}

${ }^{a}$ Reaction conditions: $1 \mathrm{a}(0.40 \mathrm{mmol}), 2 \mathrm{a}(0.20 \mathrm{mmol})$, additive $(0.20$ $\mathrm{mmol})$, reductant $(0.60 \mathrm{mmol}), \mathrm{L1d}(0.02 \mathrm{mmol}), \mathrm{NiBr}_{2}(0.02 \mathrm{mmol})$, solvent (1 mL). ${ }^{b}$ Isolated yield. ${ }^{c} x=7.5{ }^{d} x=15 .{ }^{e} x=20 .{ }^{f}$ Additive $(0.15 \mathrm{mmol}){ }^{g}$ Additive $(0.30 \mathrm{mmol})$. 
Table 3 Scope of aryl bromides in XEC ${ }^{a, b}$

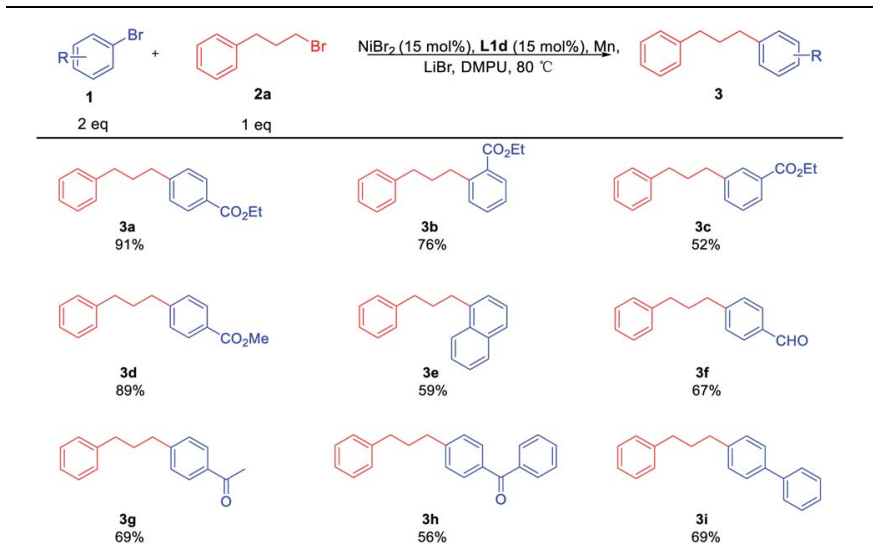

${ }^{a}$ Reaction conditions: $1(0.40 \mathrm{mmol}), 2 \mathrm{a}(0.20 \mathrm{mmol}), \mathrm{LiBr}(0.20 \mathrm{mmol})$, Mn (0.60 mmol), L1d (0.03 mmol), $\mathrm{NiBr}_{2}(0.03 \mathrm{mmol})$, DMPU $(1 \mathrm{~mL})$. ${ }^{b}$ Isolated yield.

Table 4 Scope of alkyl bromides in XEC $\mathrm{E}^{a, b}$

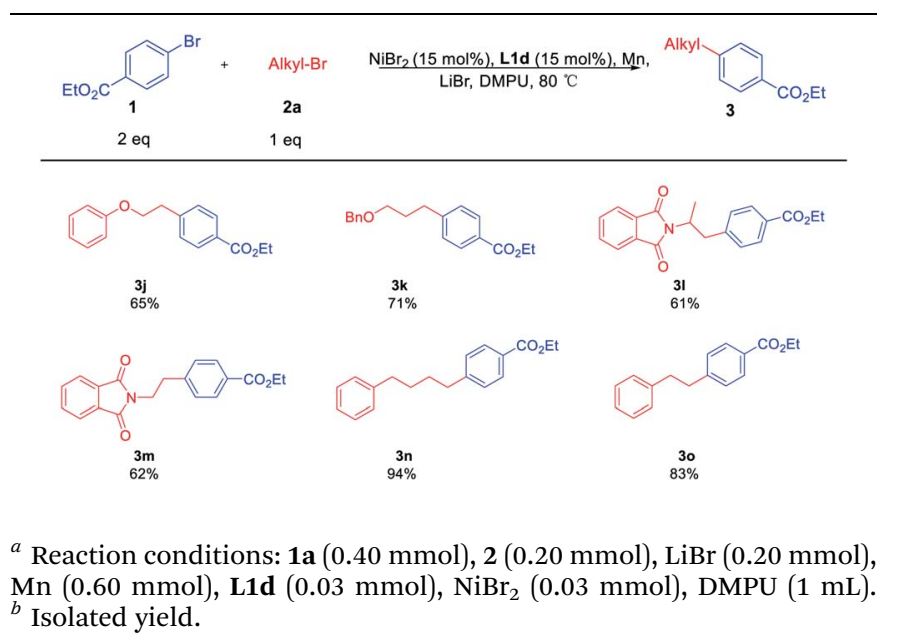

obtained in moderate yield, providing the product $3 \mathbf{c}$ in the yield of $52 \%$. Among the functional groups, the reactions were successfully observed in the presence of esters 3a-d, naphthyl $\mathbf{3 e}$, aldehyde $\mathbf{3 f}$, and ketones $\mathbf{3 g}$, $\mathbf{3 h}$. It should be noted that $\mathbf{3 f}$ is the intermediate product of $5-\mathrm{HT}_{2} \mathrm{~A} \cdot{ }^{4 c}$ The electron-rich substrate $3 \mathbf{i}$ could also be coupled with $2 \mathbf{a}$ in good yield. However, the reaction was not effective for aryl bromides bearing electron-rich reagents like 4-bromoanisole.

Then, the scope of the reaction with respect to primary alkyl bromides 2 was subsequently investigated. The results were shown in Table 4. All reactions provide the alkylated crosscoupling products smoothly. The functional groups, such as the ether $\mathbf{3} \mathbf{j}$ and benzyloxy $\mathbf{3 h}$, all worked efficiently under the standard conditions. This catalytic method was also compatible with nitrogen-containing electrophiles, as demonstrated by the coupling of 2-(1-bromopropan-2-yl)isoindoline-1,3-dione $2 \mathbf{l}$ and $N$-(2-bromoethyl)phthalimide $2 \mathrm{~m}$ with $1 \mathrm{a}$ in $61 \%$ and $62 \%$ yield, respectively. In the synthesis of the relatively longer-chain

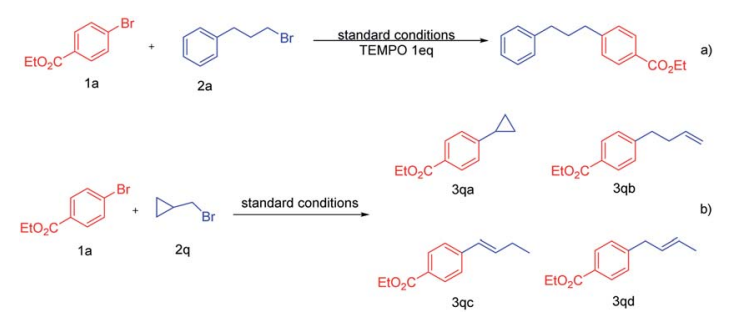

Scheme 3 Mechanistic studies.

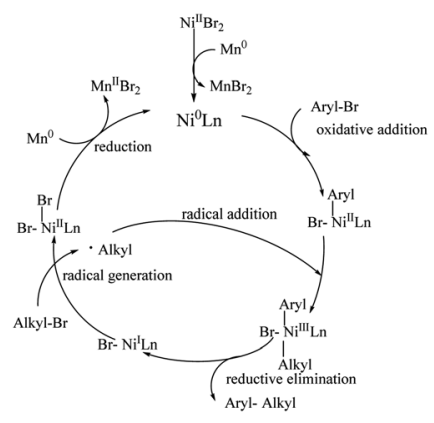

Scheme 4 The plausible mechanism.

product 3n, it was found that the coupling product was obtained in satisfactory yield. Besides, a simple shorter-chain alkyl substrate 20 was converted to 30 smoothly. These results further showed that it did not significantly influence the reaction performance when changing the alkyl chains.

To further understand the mechanism of this reaction, the radical experiment was subsequently carried out (Scheme 3). Under the standard conditions, in the presence of the radical scavenger 2,2,6,6-tetramethyl-1-piperidinyloxy (TEMPO), the cross-coupling reaction was completely blocked and no alkylated arene 3a was recorded, which implies that this transformation might undergo a free radical pathway (Scheme 3a). To further demonstrate that the alkyl bromide might follow the radical pathway, a radical clock experiment was carried out. ${ }^{13,12 d}$ We used the cyclopropylmethyl bromide $\mathbf{2 q}$ as a coupling reagent under the standard conditions, and the cross-coupling product 3qa was not detected (Scheme $3 \mathrm{~b}$ ). The reaction resulted in a mixture of products; it was found that the reaction generates the ringopened products $3 q \mathbf{q}, 3 q \mathrm{q}$ and $3 q d$ in a total $51 \%$ yield, and the ratio of $3 q b: 3 q d: 3 q e$ is about $2: 0.4: 2.4$. These results further point towards the involvement of alkyl radical intermediate generation in the coupling process of alkyl bromides.

The current mechanistic hypothesis is outlined in Scheme 4. The reaction begins with the initial reduction of the $\mathrm{Ni}^{\mathrm{II}}$ precatalyst, which can furnish a catalytically active $\mathrm{Ni}^{0} \mathrm{Ln}$ species. Subsequent oxidative addition to the aryl bromide forms an aryl- $\mathrm{Ni}^{\mathrm{II}}$ intermediate. Then, it reacts with an alkyl radical to give an aryl alkyl $\mathrm{Ni}^{\mathrm{III}}$ intermediate. Reductive elimination occurs to give the aryl-alkyl cross-coupling product along with generating the $\mathrm{Ni}^{\mathrm{I}}$ species. The radical generation gives the $\mathrm{Ni}^{\mathrm{II}}$ intermediate, which is subjected to reduction by manganese and regenerates the $\mathrm{Ni}^{0} \mathrm{Ln}$ species to complete the catalytic cycle. 


\section{Conclusions}

In conclusion, by using a $\mathrm{NiBr}_{2} / \mathbf{L 1 d}$ catalyst, the crosselectrophile coupling reactions of aryl bromides and primary alkyl bromides were developed. A variety of alkylated arene products with various functional groups could be obtained in moderate to excellent yields. The result further demonstrated that the nickel/spiro-bidentate-pyox catalytic cross-electrophile coupling protocol afforded an effective method for the synthesis of alkylated arene products. Further investigation to extend this catalytic protocol to other coupling reactions and a detailed mechanistic study are ongoing and will be reported in due course.

\section{Conflicts of interest}

There are no conflicts to declare.

\section{Acknowledgements}

The authors thank professor Longjiang Huang for the MS analysis and Dr Bo Sun for the help in experimental discussion.

\section{Notes and references}

1 (a) X. Qian, A. Auffrant, A. Felouat and C. Gosmini, Angew. Chem., Int. Ed., 2011, 50, 10402; (b) A. Krasovskiy, C. Duplais and B. H. Lipshutz, Org. Lett., 2010, 12, 4742; (c) X. L. Yu, T. Yang, S. L. Wang, H. L. Xu and H. G. Gong, Org. Lett., 2011, 13, 2138; (d) D. A. Everson, R. Shrestha and D. J. Weix, J. Am. Chem. Soc., 2010, 132, 920; (e) M. R. Prinsell, D. A. Everson and D. J. Weix, Chem. Commun., 2010, 46, 5743; ( $f$ ) R. Jana, T. P. Pathak and M. S. Sigman, Chem. Rev., 2011, 111, 1417; $(g)$ L. Ackermann, J. Org. Chem., 2014, 79, 8948; (h) Q. Cao, J. L. Howard, E. Wheatley and D. L. Browne, Angew. Chem., Int. Ed., 2018, 57, 11339; (i) S. Biswas, B. Qu, J. N. Desrosiers, Y. Choi, N. Haddad, N. K. Yee, J. J. Song and C. H. Senanayake, J. Org. Chem., 2020, 85, 8214; (j) M. Amatore and C. Gosmini, Chem.-Eur. J., 2010, 16, 5848; (k) R. J. Perkins, D. J. Pedro and E. C. Hansen, Org. Lett., 2017, 19, 3755; (l) J. A. Milligan, J. P. Phelan, S. O. Badir and G. A. Molander, Angew. Chem., Int. Ed., 2019, 58, 6152; $(\mathrm{m}) \mathrm{K}$. E. Poremba, S. E. Dibrell and S. E. Reisman, ACS Catal., 2020, 10, 8237.

2 (a) S. S. Wu, W. J. Shi and G. Zou, New J. Chem., 2021, 45, 11269; (b) D. A. Everson, B. A. Jones and D. J. Weix, J. Am. Chem. Soc., 2012, 134, 6146; (c) K. A. Johnson, S. Biswas and D. J. Weix, Chem.-Eur. J., 2016, 22, 7399; (d) P. Zhang, C. C. Le and D. W. C. MacMillan, J. Am. Chem. Soc., 2016, 138, 8084; (e) A. Paul, M. D. Smith and A. K. Vannucci, J. Org. Chem., 2017, 82, 1996; $(f)$ Y. X. Jin and C. Wang, Angew. Chem., Int. Ed., 2019, 58, 6722; $(g)$ Y. X. Jin, H. Yang and C. Wang, Org. Lett., 2020, 22, 2724; $(h)$ Y. Lan and C. Wang, Commun. Chem., 2020, 3, 1; (i) D. A. Everson and D. J. Weix, J. Org. Chem., 2014, 79, 4793; (j) D. J. Weix, Acc. Chem. Res., 2015, 48, 1767; (k) X. Wang, Y. J. Dai and
H. G. Gong, Top. Curr. Chem., 2016, 374, 43; (l) E. Richmond and J. Moran, Synthesis, 2018, 50, 499; $(\mathrm{m})$ N. T. Kadunce and S. E. Reisman, J. Am. Chem. Soc., 2015, 137, 10480; (n) J. Sheng, H. Q. Ni, H. R. Zhang, K. F. Zhang, Y. N. Wang and X. S. Wang, Angew. Chem., Int. Ed., 2018, 57, 7634.

3 (a) A. H. Cherney, N. T. Kadunce and S. E. Reisman, J. Am. Chem. Soc., 2013, 135, 7442; (b) Y. Zhao and D. J. Weix, J. Am. Chem. Soc., 2014, 136, 48; (c) C. L. Zhao, X. Jia, X. Wang and H. G. Gong, J. Am. Chem. Soc., 2014, 136, 17645; (d) M. Parasram, B. J. Shields, O. Ahmad, T. Knauber and A. G. Doyle, ACS Catal., 2020, 10, 5821; (e) A. C. Wotal and D. J. Weix, Org. Lett., 2012, 14, 1476; $(f)$ G. A. Molander, S. R. Wisniewski and K. M. Traister, Org. Lett., 2014, 16, 3692; $(g)$ S. Y. Kim, T. Iwai, S. Fujii, K. Ueno and M. Sawamura, Chem.-Eur. J., 2021, 27, 2289; (h) S. Y. Kim, M. J. Goldfogel, M. M. Gilbert and D. J. Weix, J. Am. Chem. Soc., 2020, 142, 9902; (i) J. W. Wang, J. H. Zhao and H. G. Gong, Chem. Commun., 2017, 53, 10180; (j) E. J. Barreiro, A. E. Kümmerle and C. A. M. Fraga, Chem. Rev., 2011, 111, 5215.

4 (a) D. Hoyer, D. E. Clarkena and P. P. A. Humphrey, Pharmacol. Rev., 1994, 46, 157; (b) I. V. Wijngaarden and W. Soudijn, 5- $\mathrm{HT}_{2} \mathrm{~A}, 5-\mathrm{HT}_{2} \mathrm{~B}$ and $5-\mathrm{HT}_{2} \mathrm{C}$ Receptor Ligands, in Pharmacochemistry Library, ed. B. Oliver, I. V. Wijngaarden and W. Soudijn, Elsevier, 1997, vol. 27, pp. 161-197; (c) C. S. Dowd, K. Herrick-Davis, C. Egan, A. DuPre, C. Smith, M. Teitler and R. A. Glennon, J. Med. Chem., 2000, 43, 3074.

5 J. Q. Li, J. Feng, W. P. Cai, Z. X. Zhang and T. Yin, WO 2010125908 A1, 2010.

6 A. Sasse, K. Kiec-Kononowicz, H. Stark, M. Motyl, S. Reidemeister, C. R. Ganellin, X. Ligneau, J.-C. Schwartz and W. Schunack, J. Med. Chem., 1999, 42, 593.

7 (a) L. Y. Lv, Z. H. Qiu, J. B. Li, M. X. Liu and C. J. Li, Nat. Commun., 2018, 9, 4739; (b) M. L. Zhang, R. Ruzi, J. W. Xi, N. Li, Z. K. Wu, W. P. Li, S. Y. Yu and C. J. Zhu, Org. Lett., 2017, 19, 3430.

8 D. J. Charboneau, E. L. Barth, N. Hazari, M. R. Uehling and S. L. Zultanski, ACS Catal., 2020, 10, 12642.

9 R. J. Perkins, A. J. Hughes, D. J. Weix and E. C. Hansen, Org. Process Res. Dev., 2019, 23, 1746.

10 N. X. Gao, Y. S. Li, G. R. Cao and D. W. Teng, New J. Chem., 2021, 45, 16477.

11 L. L. Anka-Lufford, K. M. M. Huihui, N. J. Gower and D. J. Weix, Chem.-Eur. J., 2016, 22, 11564.

12 (a) Y. Q. Li, Y. H. Fan and Q. F. Jia, Chin. J. Org. Chem., 2019, 39, 350; (b) L. Huang, A. M. Olivares and D. J. Weix, Angew. Chem., Int. Ed., 2017, 56, 11901; (c) W. J. Scott and J. K. Stille, J. Am. Chem. Soc., 1986, 108, 3033; (d) Y. Sumida, T. Sumida and T. Hosoya, Synthesis, 2017, 49, 3590-3601; (e) T. Kamikawa and T. Hayashi, Tetrahedron Lett., 1997, 38, 7087.

13 T. Z. Lin, Y. Y. Gu, P. C. Qian, H. X. Guan, P. J. Walsh and J. Y. Mao, Nat. Commun., 2020, 11, 5638. 